\title{
Correlation of seismic and petrologic thermometers suggests deep thermal anomalies beneath hotspots
}

\author{
Anna M. Courtier ${ }^{\mathrm{a}, *}$, Matthew G. Jackson ${ }^{\mathrm{b}}$, Jesse F. Lawrence ${ }^{\mathrm{c}}$, Zhengrong Wang ${ }^{\mathrm{d}}$, \\ Cin-Ty Aeolus Lee ${ }^{\mathrm{e}}$, Ralf Halama ${ }^{\mathrm{f}, 1}$, Jessica M. Warren ${ }^{\mathrm{b}}$, Rhea Workman ${ }^{\mathrm{g}}$, \\ Wenbo $\mathrm{Xu}^{\mathrm{h}}{ }^{\text {, Marc M. Hirschmann }}{ }^{\text {a }}$, Angela M. Larson ${ }^{\mathrm{i}}$, Stan R. Hart ${ }^{\mathrm{d}}$, \\ Carolina Lithgow-Bertelloni ${ }^{\mathrm{j}}$, Lars Stixrude ${ }^{\mathrm{j}}$, Wang-Ping Chen ${ }^{\mathrm{k}, 2}$ \\ a Department of Geology and Geophysics, University of Minnesota, Minneapolis MN 55455, USA \\ ${ }^{\mathrm{b}}$ MIT/WHOI Joint Program, Woods Hole MA 02540, USA \\ ${ }^{\mathrm{c}}$ Department of Geophysics, Stanford University, Stanford CA 94305, USA \\ ${ }^{\mathrm{d}}$ Woods Hole Oceanographic Institution, Woods Hole MA 02540, USA \\ ${ }^{\mathrm{e}}$ Department of Earth Science, Rice University, Houston TX 77005, USA \\ ${ }^{\mathrm{f}}$ Department of Geology, University of Maryland, College Park MD 20742, USA \\ ${ }^{g}$ School of Ocean and Earth Science and Technology, University of Hawaii-Manoa, Honolulu HI 96822, USA \\ ${ }^{\mathrm{h}}$ Department of Geological Sciences, University of Michigan, Ann Arbor MI 48109, USA \\ ${ }^{i}$ Department of Geosciences, The Pennsylvania State University, University Park PA 16802, USA \\ ${ }^{\mathrm{j}}$ Department of Earth Sciences, University College London, London WC1E 6BT, UK \\ ${ }^{\mathrm{k}}$ Department of Geology, University of Illinois at Urbana-Champaign, Urbana IL 61801, USA
}

Received 4 September 2007; received in revised form 2 October 2007; accepted 3 October 2007

Available online 10 October 2007

Editor: R.W. Carlson

\begin{abstract}
A fundamental question regarding the dynamics of mantle convection is whether some intraplate volcanic centers, known as "hotspots," are the surface manifestations of hot, narrow, thermally driven upwellings, or plumes, rising from the lower mantle. Shown here is a global negative correlation between the thickness of the mantle transition zone (near 410-660 km depth) and petrologically determined potential temperatures of mid-ocean ridge and hotspot magmas. Hotspot potential temperatures are systematically higher than those for mid-ocean ridges, and the transition zone thicknesses beneath these hotspots are thinner. Thus, the majority of oceanic intraplate magmatic centers are associated with deep-seated thermal anomalies, suggesting that such magmatism is probably associated with thermal plumes.
\end{abstract}

(C) 2007 Elsevier B.V. All rights reserved.

Keywords: mantle potential temperature; transition zone thickness; mantle plumes

\footnotetext{
* Corresponding author.

E-mail address: cour0090@umn.edu (A.M. Courtier).

${ }^{1}$ Currently at Institut für Geowissenschaften, Christian-AlbrechtsUniversität Kiel, 24098 Kiel, Germany.

${ }^{2}$ Currently on leave at the Institute of Earth Sciences, Academia Sinica, Taiwan, ROC.
}

\section{Introduction}

The origin of intraplate oceanic magmatic centers, usually referred to as "hotspots," is the subject of considerable controversy (Anderson, 2005). These magmatic 
centers are often located far from plate boundaries, and their sources do not appear to be strongly influenced by plate motions (Mueller et al., 1993). These observations, combined with the association of the magmatic centers with broad lithospheric swells, form the basis of a popular paradigm that "hotspots" are associated with narrow, thermally driven upwellings or plumes. The plumes are thought to rise from the lower mantle, perhaps from a hot thermal boundary layer at the base of the mantle (Morgan, 1971; Sleep, 1990).

In contrast, some have argued that all or most "hotspots" are associated with either shallow thermal perturbations, tectonically focused regions of magma upwelling, or compositional variations without any thermal anomaly (Anderson, 2000; Green et al., 2001; Foulger and Natland, 2003). In the first scenario, intraplate magmatism is produced by hot regions that are confined to the shallow upper mantle. In the second, "plate-fracture" scenario, cracks in the lithosphere induced by tectonic stresses provide magma passage to the surface and the formation of linear volcanic chains (Natland, 1980; Foulger and Natland, 2003). In the third case, melting is associated with local patches of fertile upper mantle (Green et al., 2001) that is more fusible than a typical peridotitic composition.

In any case, whole mantle convection is implied by geophysical observations of slab penetration into the deep mantle (Jordan, 1997; Van der Hilst et al., 1997; Grand et al., 1997), and part of the return flow from subduction may be compensated by deep-seated upwelling plumes. Geochemical evidence is consistent with this hypothesis, and argues for exchange between the upper and lower mantle (O'Nions and Tolstikhin, 1996; Porcelli and Wasserburg, 1995; Allègre et al., 1996). Additionally, many dynamic convection models of the mantle suggest that plumes are features of the deep earth (Brunet and Yuen, 2000; Lowman et al., 2004; Schubert et al., 2004). However, while seismic imaging of plumes has yielded some promising results (Wolfe et al., 1997; Montelli et al., 2004, 2006), the measurements are non-trivial and controversial (e.g., Foulger et al., 2006).

\section{Study objectives}

A resolution to this debate is necessary for understanding the interior dynamics of the Earth. The purpose of this paper is thus to determine whether the mantle source regions of "hotspots" are indeed hotter than the normal upper mantle underlying mid-ocean ridges, an issue that will help resolve whether "hotspots" are the result of thermally driven, deep-seated plumes.
There have been a number of attempts to address this debate. For example, temperatures of "hotspot" magmas have been estimated from petrology (Green et al., 2001; Herzberg et al., 2007; Putirka, 2005) and from swell topography (Sleep, 1990). The mantle beneath "hotspots" has been seismically imaged (e.g., Montelli et al., 2004, 2006), and upwelling rates beneath "hotspots" have been estimated using short-lived radiogenic nuclides (Bourdon et al., 2006). Finally, signatures of core contamination have been sought (Brandon et al., 1998). However, each approach carries assumptions and uncertainties that have been challenged.

To overcome the ambiguities associated with a singular approach, we examine the relationship between petrologically constrained potential temperature beneath "hotspots" and the thickness of the underlying mantle transition zone (the region between the 410 - and $660-\mathrm{km}$ seismic discontinuities that separates the upper mantle from the lower mantle). Potential temperature is the temperature of a given portion of the mantle if it were adiabatically decompressed to the surface of the Earth. Since the mantle is likely a vigorously convective system whose temperature profile closely follows the adiabatic gradient, potential temperature serves as a convenient way to compare temperatures of different regions by removing the effect of source depth. Due to the opposite sense of the pressure-temperature dependence of the phase transformations at the 410- and 660$\mathrm{km}$ discontinuities (defined by the Clapeyron slopes), there should be a negative correlation between transition zone thickness and mantle potential temperature as shown by the sloped line in Fig. 1 (Bina and Helffrich, 1994). Thus, if "hotspots" are associated with deepseated thermal anomalies, we would expect "hotspots" to be underlain by a transition zone that is thinner than the globally averaged value and to be characterized by primary magmas that are hotter than the normal upper mantle sampled by mid-ocean ridges.

\section{Petrologic calculation of mantle potential temperature}

\subsection{Methodology for petrologic calculations}

We calculated temperatures of primary mid-ocean ridge basalts (MORBs) from five ridge systems and of primary ocean island basalts (OIBs) from thirteen active oceanic "hotspots" using major element data compiled from the RidgePetDB and GEOROC databases (Fig. 2). By "primary," we are referring to the magma while it was still in its mantle source region. Samples from oceanic plateaus or continental basalts were not included in the 


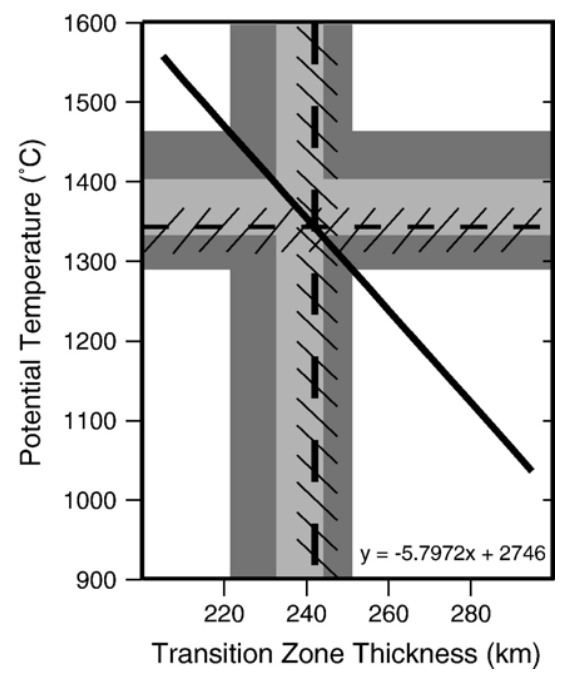

Fig 1. Transition zone thickness $(z)$ and corresponding potential temperature $\left(T_{\mathrm{p}}\right)$ assuming an adiabatic temperature gradient and a pyrolitic mantle. Solid line shows the relationship between potential temperature and transition zone thickness computed from the thermodynamic model of Stixrude and Lithgow-Bertelloni (2005). For vertical bands, dark gray shading indicates the observed range of transition zone thickness at ocean islands from receiver functions (Chevrot et al., 1999; Hooft et al., 2003; Lawrence and Shearer, 2006; Li et al., 2000; Li et al., 2003; Shen et al., 1998), light gray and hatched areas indicate observed range from SS-precursors (Lawrence and Shearer, in press) at "hotspots" and ridges, respectively. The vertical dashed line is the global average for transition zone thickness (Flanagan and Shearer, 1998a; Gu et al., 1998; Lawrence and Shearer, 2006). Horizontal bands are uncertainties in potential temperature $D T_{\mathrm{p}}=\mathrm{d} T_{\mathrm{p}} / \mathrm{d} z^{*} D Z$ propagated from uncertainties in the seismologically observed transition zone thickness, $D Z$, and the relationship from the model of Stixrude and Lithgow-Bertelloni (2005), $\mathrm{d} T_{\mathrm{p}} / \mathrm{d} z$.

analysis. The "hotspot" dataset we analyzed resulted from the application of the following filters to all available OIB data in the databases. First, we filtered out rocks that have suffered post-eruptive alteration effects by excluding samples with totals $<98$ wt.\%, $>102$ wt.\%, or with loss on ignition $>2$ wt. $\%$. Similar to Class and Goldstein (2005), we consider only alkali basalts, basalts, tholeiites, and equivalent rock types. Thus, we filtered out evolved rocks that have suffered extensive fractional crystallization (e.g., rhyolites, dacites, andesites, trachites, phonolites, and their equivalents) and rocks that originate by very low degrees of partial melting (e.g., basanites, nephelinites, and their equivalents). Samples with $\mathrm{SiO}_{2}$ contents $<46$ wt. $\%$ were excluded in order to avoid biases towards high temperatures introduced by the magmas' associations with high $\mathrm{CO}_{2}$ content, low melt fractions, and potential sampling of non-peridotitic components within the source. Filtering out these silica-undersaturated magmas eliminates much or all of the data from some "hotspots" (e.g., Cape Verde).
Compositions of these erupted lavas were then backcorrected to their primary parental compositions by reversing the crystallization process, under the assumption that that almost all magmas have undergone fractional crystallization at depth by the time they erupt. To do this, only samples with $\mathrm{MgO}$ contents between 8 and 14 wt.\% were retained to ensure that all samples fell on an olivine-dominated fractionation control line $(\mathrm{MgO}>8$ wt.\%), an assumption that is more conservative than earlier fractionation-correction schemes that included lavas with a larger range of $\mathrm{MgO}$ contents (e.g., 6.5 to over 18 wt.\%; Hauri, 1996). Compositions above 14 wt. $\% \mathrm{MgO}$ were discarded in order to avoid olivine accumulation into the magma. Fractional crystallization was then "reversed" by incrementally adding equilibrium olivine back into the evolved magma, resulting in an increase in liquid $\mathrm{MgO}$. Liquid and olivine compositions at each increment were controlled by $\mathrm{Fe}-\mathrm{Mg}$ equilibrium, e.g., $K_{\mathrm{D}}(\mathrm{Fe} / \mathrm{Mg})$, between olivine and melt (Herzberg et al., 2007; Toplis, 2005). We accounted for the slight variation of $K_{\mathrm{D}}$ with melt composition (Toplis, 2005), but did not account for the effect of pressure on $K_{\mathrm{D}}$ because we have no independent estimate of pressure. Finally, our calculations assumed an $\mathrm{Fe}^{3+} / \mathrm{Fe}_{\text {total }}$ cation ratio of $\sim 0.9$, which corresponds to an oxygen fugacity near the fayalitemagnetite-quartz buffer characteristic of both MORBs (Bezos and Humler, 2005) and OIBs (Rhodes and Vollinger, 2005).

We equated the primary liquid composition to the calculated composition of the liquid as soon as the olivine increment attained a forsterite content of 90 (Fo90; atomic $\left.[\mathrm{Mg} /(\mathrm{Mg}+\mathrm{Fe})]^{*} 100=90\right)$. This stopping point was assumed for all samples, and the temperature of the primary magma was then determined

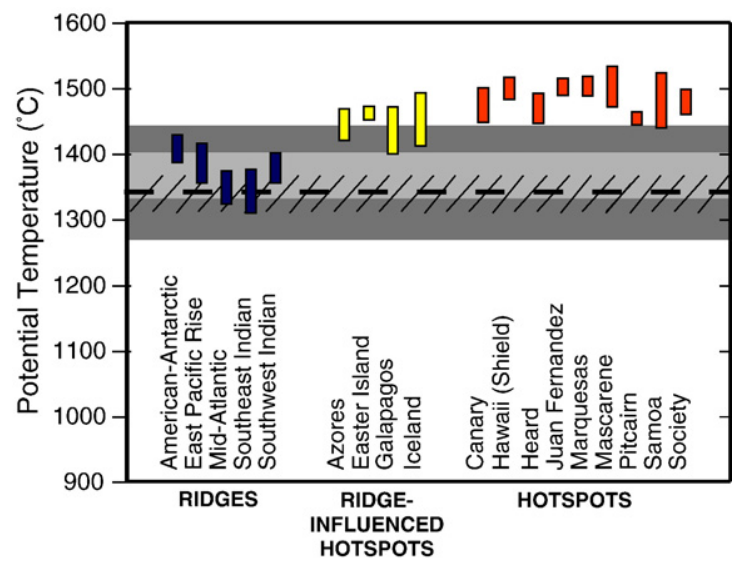

Fig. 2. Petrologically determined mantle potential temperatures for ridges and "hotspots." Horizontal bands are the same as those in Fig. 1. 
from the liquid-olivine distribution of $\mathrm{MgO}$ following the recent calibrations of Putirka (2005). Magmas with high $\mathrm{MgO}$ content yield high temperatures. Because our back-additions of olivine terminate at the same forsterite content of olivine, magmas with low $\mathrm{FeO}$ content (most MORBs) require less addition of olivine than magmas with high $\mathrm{FeO}$ content (most OIBs). This means that the inferred primary liquid compositions of low $\mathrm{FeO}$ magmas will be low in $\mathrm{MgO}$ and hence yield lower temperatures.

The largest uncertainty in the estimated temperature is the forsterite content of the olivine at which we terminate the back-addition of olivine. This forsterite content represents the composition of the residual mantle that the primary magma equilibrated with before it ascended into crustal levels. The primary magma, however, is actually an aggregate or pool of fractional melts formed during decompressional melting and is therefore a weighted average of small degree melts generated at different depths. During fractional decompression melting, the residual mantle becomes progressively more depleted (and attains higher forsterite content) with decompression; hence the composition of the pooled primary magma should roughly reflect the average pressure and temperature of the decompression column. Thus, what is of interest is the average forsterite content of olivine in the pooled primary magma, not the maximum forsterite content observed, which would essentially represent xenocrystic olivine phenocrysts formed in low pressure melt fractions. Olivine phenocrysts in both MORBs and OIBs often exceed Fo91 (Herzberg et al., 2007). Terminating at such high forsterite contents would not only yield higher temperatures but also magnify the inferred temperature differences between calculated primary liquids for MORBs and OIBs. This is because the decompression melting column for MORBs is longer, and so the final pressure of melting is significantly lower than the average pressure of the melting column. In contrast, because of the capping effect of a thick, over-riding lithosphere, the melting column beneath hotspots is shorter and hence the difference between average and final pressure of melting is much smaller. Our choice of Fo90 (which is lower than the maximum observed forsterite contents in MORBs and OIBs) is thus a minimum bound on both absolute temperature and temperature differences.

We also need to consider the case in which OIBs derive from a more fertile source such that OIBs correct back to forsterite contents lower than that of MORB. A number of studies have suggested that the source regions of some OIB magmas may be more fertile than ambient upper mantle (e.g., Sobolev et al., 2005). However, the effect of a more fertile starting composition is somewhat irrelevant because, as discussed above, the key to our temperature calculations is estimating the forsterite content of the average residual mantle (not the original unmelted mantle) left behind after magma extraction. The preponderance of olivine control and the abundance of olivine phenocrysts with Fo $>89$ in nearly all OIBs, even those suggested to have originally come from an olivine-free source at great depth (Sobolev et al., 2005), means that our estimates of magmatic temperatures, particularly for OIBs, are still minimum values. Our assumptions are well in line with the independent and more sophisticated calculations of Herzberg et al. (2007) on a smaller selection of OIBs and MORBs.

A third uncertainty arises from the assumption of pure olivine fractionation. While this may indeed be the case for OIBs, MORBs often co-crystallize along olivineplagioclase-augite cotectics. Because plagioclase has zero $\mathrm{MgO}$ and augite lower $\mathrm{MgO}$ than olivine, backcorrecting an evolved magma along such a cotectic would give low $\mathrm{MgO}$ contents, yielding slightly lower temperatures $\left(<50^{\circ} \mathrm{C}\right)$. Thus, any temperature difference we calculate between OIBs and MORBs is a minimum.

Finally, all of our primary liquid temperatures should in theory be converted to potential temperatures by correcting for the latent heat of fusion during decompressional melting and then extrapolating temperatures along a solid adiabat to the surface of the Earth. Making such corrections is not trivial, because the decompression melting process could be very complicated. We can, however, approximate these correction factors as follows. Assuming that the magma and solid remain together during decompressional melting (in a closed system) and that there is no conductive heat loss of the system to the surroundings, the total temperature drop of the system is equal to the total heat of fusion divided by the heat capacity of the system, e.g., $\Delta T=H_{\text {fus }} / C_{\mathrm{p}}$. For a given degree of melting $F$ (the mass of melt divided by the total mass of system), the temperature drop is $\Delta T_{F} \sim\left(H_{\text {fus }} / C_{\mathrm{p}}\right) F$, which can be further approximated by $\Delta T_{F} \sim\left(T \Delta S / C_{p}\right) F \sim(T / 3) F$, where $T$ is the average temperature over which melting occurs, $\Delta S$ is the total entropy change during melting, and the approximation $\Delta S \sim 3 C_{\mathrm{p}}$ is adopted. Thus, the difference in potential temperatures between two primary magmas $A$ and $B$ is less than the difference between the primary magma temperatures by approximately $(T / 3)\left(F_{B}-F_{A}\right)$. If the average melting degrees for OIB and MORB magmas are equal, then the differences in their primary magmatic temperatures need not be corrected. However, this is not generally the case. The average melting degree for 
MORBs is $\sim 7 \%$ (Workman and Hart, 2005), whereas that for OIBs is probably smaller, albeit highly variable. A maximum estimate of the correction can be obtained by assuming that the melting degrees for OIBs are very small (e.g., $F=0$ ), thus the difference in potential temperature between "hotspots" and MORBs is less than the measured primary magma temperature difference by at most $\sim 20-40{ }^{\circ} \mathrm{C}$, which is smaller than the observed differences in temperatures between OIBs and MORBs.

\subsection{Results of petrologic calculations}

Calculated primary magma temperatures are shown in Table 1 and as vertical bars in Fig. 2. MORBs yield source region temperatures between $1300-1400{ }^{\circ} \mathrm{C}$, while OIBs away from spreading ridges (e.g., Hawaii) yield systematically higher temperatures $\left(1450-1550{ }^{\circ} \mathrm{C}\right)$. OIBs on or near spreading ridges, such as Iceland, the Azores, Easter Island, and the Galapagos Islands, yield intermediate temperatures $\left(1400-1500{ }^{\circ} \mathrm{C}\right)$. Although our temperature

Table 1

Potential temperature and transition zone thickness for each location included in the study

\begin{tabular}{|c|c|c|c|c|c|c|c|c|}
\hline Location & Lat & Lon & $\begin{array}{l}\# \text { of } \\
\text { samples }^{\text {a }}\end{array}$ & $\begin{array}{l}\text { Potential temp } \\
\text { (C) }\end{array}$ & Error $^{b}$ & $\begin{array}{l}\text { WTZ } \\
(\mathrm{km})\end{array}$ & Error $^{\mathrm{b}}$ & References $^{c}$ \\
\hline \multicolumn{9}{|l|}{ Ridges } \\
\hline Mid-Atlantic & 1.1 to 29.8 & $\begin{array}{l}-30.4 \text { to } \\
-46.7\end{array}$ & 138 & 1407 & 21 & 245 & 2 & $\begin{array}{l}\text { Lawrence and Shearer } \\
\text { (in press) }\end{array}$ \\
\hline East Pacific Rise & 15.8 to 27.1 & $\begin{array}{l}-105.4 \text { to } \\
-111.5\end{array}$ & 82 & 1385 & 30 & 239 & 2 & $\begin{array}{l}\text { Lawrence and Shearer } \\
\text { (in press) }\end{array}$ \\
\hline Southeast Indian & -25.9 to -49.9 & 88.9 to 124 & 89 & 1348 & 25 & 240 & 2 & $\begin{array}{l}\text { Lawrence and Shearer } \\
\text { (in press) }\end{array}$ \\
\hline Southwest Indian & -27.6 to -54.4 & 5.1 to 65.8 & 22 & 1343 & 33 & 246 & 2 & $\begin{array}{l}\text { Lawrence and Shearer } \\
\text { (in press) }\end{array}$ \\
\hline American-Antarctic & -55.8 to -58.7 & -3.9 to -16.2 & 9 & 1378 & 23 & 242 & 2 & $\begin{array}{l}\text { Lawrence and Shearer } \\
\text { (in press) }\end{array}$ \\
\hline \multicolumn{9}{|c|}{ Ridge-influenced hotspots } \\
\hline Azores & 38.75 & -28 & 18 & 1443 & 24 & 239 & 4 & $\begin{array}{l}\text { (Lawrence and Shearer in press; } \\
\text { Li et al., 2003) }\end{array}$ \\
\hline Easter Island & -27 & -108 & 12 & 1462 & 10 & 246 & 3 & $\begin{array}{l}\text { (Chevrot et al., 1999; Lawrence and } \\
\text { Shearer, in press; Li et al., 2003) }\end{array}$ \\
\hline Galapagos & 0 & -92 & 82 & 1431 & 33 & 226 & 3 & $\begin{array}{l}\text { (Hooft et al., 2003; Lawrence } \\
\text { and Shearer, in press) }\end{array}$ \\
\hline Iceland & 64 & -17 & 485 & 1452 & 42 & 238 & 2 & $\begin{array}{l}\text { (Lawrence and Shearer, 2006; } \\
\text { Lawrence and Shearer, in press; } \\
\text { Shen et al., 1998) }\end{array}$ \\
\hline \multicolumn{9}{|l|}{ Hotspots } \\
\hline Canary & 28.1 & -15.4 & 75 & 1473 & 25 & 238 & 4 & $\begin{array}{l}\text { (Lawrence and Shearer, in press; } \\
\text { Li et al., 2003) }\end{array}$ \\
\hline Hawaii (Shield) & 19.75 & -155 & 1094 & 1499 & 17 & 235 & 2 & $\begin{array}{l}\text { (Lawrence and Shearer, 2006; } \\
\text { Lawrence and Shearer, in press; } \\
\text { Li et al., 2000) }\end{array}$ \\
\hline Heard & -53.1 & 72.5 & 12 & 1469 & 23 & 238 & 5 & Lawrence and Shearer (in press) \\
\hline Juan Fernandez & -34 & -81 & 7 & 1501 & 13 & 242 & 5 & Lawrence and Shearer (in press) \\
\hline Marquesas & -9 & -139.5 & 12 & 1500 & 16 & 239 & 4 & Lawrence and Shearer (in press) \\
\hline Mascarene & -21 & 57 & 52 & 1501 & 31 & 238 & 4 & Lawrence and Shearer (in press) \\
\hline Pitcairn & -25.7 & -130.1 & 14 & 1453 & 10 & 229 & 2 & $\begin{array}{l}\text { (Lawrence and Shearer, 2006; } \\
\text { Lawrence and Shearer, in press; } \\
\text { Li et al., 2003) }\end{array}$ \\
\hline Samoa & -13.5 & -171.75 & 23 & 1480 & 22 & 235 & 2 & $\begin{array}{l}\text { (Chevrot et al., 1999; Lawrence } \\
\text { and Shearer, 2006; Lawrence and } \\
\text { Shearer, in press; Li et al. 2003) }\end{array}$ \\
\hline Society & -17 & -150 & 12 & 1476 & 20 & 233 & 4 & Lawrence and Shearer (in press) \\
\hline
\end{tabular}

${ }^{a}$ Number of rock samples used for potential temperature calculation.

b One standard deviation uncertainties reported.

c References for seismic transition zone thickness measurements. 
estimates for OIBs are slightly lower than that of Herzberg et al. (2007) and Putirka (2005) due to the slightly different assumptions taken above, the sense of the temperature differences is similar to these two studies. Primary OIBs are generally hotter than primary MORBs.

\section{Seismic transition zone thickness observations}

\subsection{Methodology for seismic measurements}

We now turn to seismic constraints on mantle potential temperature as constrained by transition zone thickness beneath "hotspots" and ambient mantle (ridges). While there are many techniques for measuring the lateral variations in depth of the $410-$ and $660-\mathrm{km}$ discontinuities, the most common methods are P- and S-wave triplication (Grand and Helmberger, 1984; Kennett and Engdahl, 1991; Walck, 1984), near-source converted phases (Flanagan and Shearer, 1998b; Wicks and Richards, 1993), receiver functions (Lawrence and Shearer, 2006; Li and Detrick, 2003; Vinnik, 1977), and SS-precursors (Flanagan and Shearer, 1998a; Gu et al., 1998; Lawrence and Shearer, in press; Shearer, 1993). Triplicated P- and S-waves are of high resolution but only occur at distances between $13^{\circ}$ and $33^{\circ}$ from the source, so the lateral coverage is limited. Near-source converted phases (e.g., $p 410 P, s 410 P, S 410 P, S 660 P$ ) are commonly used to study the transition zone discontinuities and also provide high resolution, but this method is not as useful for studies beneath "hotspots" due to the lack of local seismicity. Receiver functions rely on P-to-S conversions across deep interfaces beneath and near seismic stations, providing resolution on the order of $100 \mathrm{~km}$, though coverage is limited to locations where seismic stations exist. SS-precursors provide global coverage with sensitivities near a reflection point from the underside of interfaces at depth, but at the cost of low spatial resolution $(\sim 1000 \mathrm{~km})$. We discuss receiver functions and SSprecursors here. Since there are many locations where receiver function results are not possible due to the limited distribution of seismic stations, we use results from SSprecursors to "stabilize" our results. Where receiver function and SS-precursor results overlap, there is correlation between the two, suggesting that the two are sensitive to similar structures (Lawrence and Shearer, 2006) despite differences in the spatial resolution of each method.

There are multiple challenges to resolving the topography on the 410 - and $660-\mathrm{km}$ discontinuities. First, the impedance contrasts across the discontinuities are small, so the amplitudes of the relevant phases are often at or below the level of the ambient noise. Stacking of repeated observations is commonly invoked to increase signal-to-noise ratios, and differences in processing and stacking methods often lead to discrepancies between results reported from different studies. Additionally, the trade-off between depth and seismic velocity can bias the estimated depth to the interface if an inaccurate velocity model is used. The most robust results involve the relative thickness of the transition zone rather than individual topographies for each interface, because the relative thickness is less biased by differences in methods and the assumed crust and upper mantle velocity models.

Although receiver function studies generally provide similar patterns of thickening and thinning on a global scale, the individual results often differ significantly for several reasons. For the same technique, measurements can differ for a single seismic station depending on back-azimuth (the direction to the earthquake from the receiver), because the structure may be different on one side of the station relative to the other (Dueker and Sheehan, 1998). Some studies stack receiver functions from all available back azimuths, a practice that tends to damp short-wavelength variations and likely underestimates the topographic variation (Lawrence and Shearer, 2006). Other studies back-project seismic ray paths during stacking to calculate the P-to-S conversion depths, which can cause 2-4 km of bias in depths due to issues regarding the ray parameter (see Lawrence and Shearer (2006) for further details). We have corrected all receiver function data for this bias in our study.

Despite discrepancies between various results and the difficulties involved in measuring transition zone topography, many robust and repeatable observations have been made (Table 1). The first order observation is that the average transition zone thickness is $242 \pm 2 \mathrm{~km}$ (Flanagan and Shearer, 1998a; Gu et al., 1998; Lawrence and Shearer, 2006), not $250 \mathrm{~km}$ as the labels " 410 " and "660" suggest. Second, the transition zone thickens near subduction zones and thins elsewhere (Chevrot et al., 1999; Flanagan and Shearer, 1998a; Lawrence and Shearer, 2006). In order to examine whether there is an additional, global-scale thinning of the transition zone beneath "hotspots," we compare transition zone thickness results from a variety of receiver function (Chevrot et al., 1999; Hooft et al., 2003; Lawrence and Shearer, 2006; Li et al., 2000; Li et al., 2003; Shen et al., 1998) and SS-precursor (Lawrence and Shearer, in press) studies for regions beneath both mid-ocean ridges and "hotspots." Because of the variability between receiver function results, we convert travel times to estimated depths for each location by interpolating between a series of ray theoretical IASP91 travel times (Kennett and Engdahl, 1991) for waves that converted from $P$ to $S$ at $25 \mathrm{~km}$ depth intervals 
from 200 to $1000 \mathrm{~km}$ depth. For values obtained with SSprecursors, the average transition zone thickness within a $2^{\circ}$ radius of the nominal "hotspot" location was calculated since the precise location of the "hotspot" source is unknown. The best resolution of the latest model is $2-4^{\circ}$ (Lawrence and Shearer, in press).

\subsection{Results of seismic measurements}

The average transition zone thickness beneath the analyzed "hotspots" is $234 \pm 1 \mathrm{~km}, \sim 8 \mathrm{~km}$ thinner than both the average value for ridges included in this study $(242 \pm 1 \mathrm{~km})$ and the global average $(242 \pm 2 \mathrm{~km})$. When multiple measurements of transition zone thickness were available at a given location (see "References" column in Table 1), the results we report were weighted according to the reported errors of individual measurements. Therefore, measurements that are of poorer resolution contribute less to the final value that is reported for the location. This was completed for averages at individual locations and for the values report above within the ridge and "hotspot" categories. Since the resolution of the seismic data is large compared to the expected length scale of the potential plume feeding the "hotspot," the observed thinning estimated with the seismic methods may be greatly damped. Hence these results represent a lower bound on thinning of the transition zone near hotspots. The true uncertainties of the measurements are probably somewhat larger than those cited here, because consistent sets of criteria for estimating errors were not used in the various seismic studies used to obtain transition zone thickness measurements. However, even if uncertainties on transition zone thickness are larger than we report, our results do not change significantly.

\section{Discussion}

In Fig. 1, we relate transition zone thicknesses with mantle potential temperature based on thermodynamic calculations of phase proportions as a function of temperature and pressure for a pyrolitic composition (Stixrude and Lithgow-Bertelloni, 2005). It can be seen that the global average transition zone thickness corresponds to an average potential temperature of $\sim 1350{ }^{\circ} \mathrm{C}$, which falls within our petrologic estimates of potential temperature beneath ridges. The combination of transition zone thickness, petrologic, and thermodynamic approaches constrain the average potential temperature of the Earth to be between $1300-1400{ }^{\circ} \mathrm{C}$, the same range reported by Herzberg et al. (2007).

We now combine observed transition zone thicknesses and petrologically determined potential temperatures for
OIBs and MORBs (Fig. 3). Although there is scatter in the data, Fig. 3 shows that there is a hint of a negative correlation between petrologically determined temperature and the seismically determined thickness of the underlying transition zone. The negative correlation seen in mid-ocean ridges and active "hotspots" suggests that at least some "hotspots" are not only underlain by thermal anomalies but that these thermal anomalies penetrate through the transition zone. We note, however, that the slope of the negative correlation in the data does not exactly match the theoretical predictions (sloped line in Fig. 3); the observed change in transition zone thickness is smaller than that expected from the petrologically determined temperature differences between OIBs and MORBs. However, our data follow the expected bias toward thicker transition zone measurements for "hotspots" given the difference in the spatial resolution of the seismic and petrologic approaches. The petrologic approach samples the hottest part of the "hotspot" (the plume core) while the seismological approach averages out the transition zone thickness over 100-400 km length scales (the plume halo, and potentially additional surrounding "normal" mantle), dampening the measured anomaly in transition zone thickness. The transition zone thickness could also be biased towards thicker

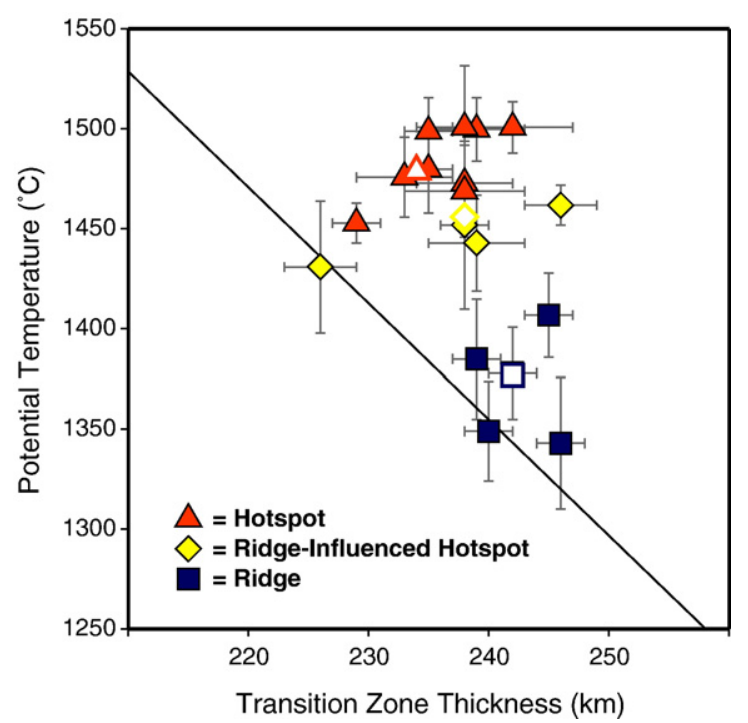

Fig. 3. Petrologically determined mantle potential temperatures and seismically determined thickness of the underlying transition zone along with error bars representing one standard deviation. Open symbols are the average of the corresponding solid symbols. Sloped line represents the theoretical relationship between transition zone thickness and potential temperature as shown in Fig. 1. Although there is scatter in the data, note that "hotspots" are on average characterized by hotter potential temperatures and thinner transition zone thicknesses than ridges. 
measurements through the effects of the garnet component of the mantle near $660 \mathrm{~km}$ depth or through the addition of water into the transition zone (Deuss et al., 2006; Higo et al., 2001; Smyth and Frost, 2002), as well as additional averaging of nearby tectonic features such as cratons (e.g., Canary Islands) or subduction zones (e.g., Juan Fernandez), factors that are not included in our comparison. In all cases, these potential biases skew the seismic measurements towards larger transition zone thicknesses. Correction for these factors would pull our measurements towards the predicted values, enhancing any negative correlation between transition zone thickness and mantle potential temperature.

\section{Conclusions}

Our results provide the first indication of a possible global negative correlation between petrologically determined potential temperature and transition zone thickness beneath mid-ocean ridges and hotspots. Our observations suggest that most hotspots are indeed hot and that these thermal anomalies are deep-seated. Does this then require that hot narrow plumes of deep origin exist? The only other places where consistent deviations in transition zone thickness have been observed on a global scale are in subduction zones (e.g., Lawrence and Shearer, 2006) where cold, down-going lithosphere enters the transition zone and sometimes even reaches the core-mantle boundary (Fukao et al., 2001). Even the strong lateral temperature variations seen in the uppermost mantle associated with variations in lithospheric thickness do not appear to perturb the transition zone. For example, the thickest continental roots do not disturb the $410-\mathrm{km}$ discontinuity (Niu et al., 2004), consistent with estimates of lithosphere thickness based on xenolith constraints (Lee et al., 2005). We thus conclude that since the hot thermal anomalies beneath hotspots appear to have disturbed the transition zone, these thermal anomalies might also extend into the lower mantle. Our results do not rule out the possibility that some intraplate magmatism is facilitated by melting of fertile components, such as garnet pyroxenites, recycled oceanic crust, and hydrated mantle. However, our geophysical and petrologic results suggest that deep-seated and narrow thermal upwellings, or mantle plumes, exist.

\section{Acknowledgments}

The authors thank reviewer Claude Herzberg, three anonymous reviewers, and editor Richard Carlson for helpful comments and reviews. This manuscript originated from a small discussion group at the 2006 CIDER workshop at the Kavli Institute of Theoretical Physics at the University of California at Santa Barbara. We thank the following for organizing or helping out in the workshop: B. Romanowicz, A. Dziewonski, T. Duffy, A. Levander, A. Sheehan, G. Masters, L. Kellogg, S. Mukhopahdyay, M. Billen and K. Cooper. Discussions with D. Anderson, P. Asimow, C. Herzberg, W. Leeman, A. Lenardic, K. Putirka, and S. Zhong are greatly appreciated. GMT software (Wessel and Smith, 1998) was used to prepare the figures. CIDER and the authors were supported by the US National Science Foundation.

\section{References}

Allègre, C.J., Hofmann, A.W., O’Nions, R.K., 1996. The argon constraints on mantle structure. Geophys. Res. 23, 3555-3557.

Anderson, D.L., 2000. The thermal state of the upper mantle; no role for mantle plumes. Geophys. Res. Lett. 27, 3623-3626.

Anderson, D.L., 2005. Scoring hotspots; the plume and plate paradigms; plates, plumes, and paradigms. Spec. Pap.-Geol. Soc. Am. 388, 31-54.

Bezos, A., Humler, E., 2005. The $\mathrm{Fe}^{3+} / \mathrm{Fe}$ ratios of MORB glasses and their implications for mantle melting. Geochim. Cosmochim. Acta 69, 711-725.

Bina, C.R., Helffrich, G., 1994. Phase transition Clapeyron slopes and transition zone seismic discontinuity topography. J. Geophys. Res. 99, 15,853-15,860.

Bourdon, B., Ribe, N.M., Stracke, A., Saal, A.E., Turner, S.P., 2006. Insights into the dynamics of mantle plumes from uranium-series geochemistry. Nature 444, 713-717.

Brandon, A.D., Walker, R.J., Morgan, J.W., Norman, M.D., Prichard, H.M., 1998. Coupled ${ }^{186}$ Os and ${ }^{187}$ Os evidence for core-mantle interaction. Science 280, 1570-1573.

Brunet, D., Yuen, D.A., 2000. Mantle plumes pinched in the transition zone. Earth Planet. Sci. Lett. 178, 13-27.

Chevrot, S., Vinnik, L., Montagner, J., 1999. Global-scale analysis of the mantle Pds phases. J. Geophys. Res. 104, 20,203-20,219.

Class, C., Goldstein, S.L., 2005. Evolution of helium isotopes in the Earth's mantle. Nature 436, 1107-1112.

Deuss, A., Redfern, S.A.T., Chambers, K., Woodhouse, J.H., 2006. The nature of the 660-kilometer discontinuity in Earth's mantle from global seismic observations of PP precursors. Science 311, 198-201.

Dueker, K.G., Sheehan, A.F., 1998. Mantle discontinuity structure beneath the Colorado Rocky Mountains and High Plains. J. Geophys. Res. 103, 7153-7169.

Flanagan, M.P., Shearer, P.M., 1998a. Global mapping of topography on transition zone velocity discontinuities by stacking SS precursors. J. Geophys. Res. 103, 2673-2692.

Flanagan, M.P., Shearer, P.M., 1998b. Topography on the $410-\mathrm{km}$ seismic velocity discontinuity near subduction zones from stacking of sS, sP, and pP precursors. J. Geophys. Res. 103, 21,165-21,183.

Foulger, G.R., Natland, J.H., 2003. Is "hotspot" volcanism a consequence of plate tectonics. Science 300, 921-922.

Foulger, G.R., Fitton, J.G., Presnall, D.C., Morgan, W.J., 2006. Chapman Conference: The Great Plume Debate The Origin and Impact of LIPs and Hot Spots, Scientific report. EOS Trans. AGU, vol. 87 , pp. 76-80.

Fukao, Y., Widiyantoro, S., Obayashi, M., 2001. Stagnant slabs in the upper and lower mantle transition region. Rev. Geophys. 39, 291-323. 
Grand, S.P., Helmberger, D.V., 1984. Upper mantle shear structure of North America. Geophys. J. R. Astron. Soc. 76, 399-438.

Grand, S.P., van der Hilst, R.D., Widiyantoro, S., 1997. Global seismic tomography: a snapshot of convection in the Earth. GSA Today 7, 1-7.

Green, D.H., Falloon, T., Eggins, S.M., Yaxley, G.M., 2001. Primary magmas and mantle temperatures; experimental mineralogy, petrology and geochemistry. Eur. J. Mineral. 13, 437-451.

Gu, Y., Dziewonski, A.M., Agee, C.B., 1998. Global de-correlation of the topography of transition zone discontinuities. Earth Planet. Sci. Lett. 157, 57-67.

Hauri, E.H., 1996. Major element variability in the Hawaiian mantle plume. Nature 382, 415-419

Herzberg, C., Asimow, P.D., Arndt, N., Niu, Y., Lesher, C.M., Fitton, J.G., Cheadle, M.J., Saunders, A.D.T., 2007. Temperatures in ambient mantle and plumes: constraints from basalts, picrites, and komatiites. Geochem. Geophys. Geosystems 8. doi:10.1029/2006GC001390.

Higo, Y., Inoue, T., Irifune, T., Yurimoto, H., 2001. Effect of water on the spinel-postspinel transformation in $\mathrm{Mg}_{2} \mathrm{SiO}_{4}$. Geophys. Res. Lett. 28, 3505-3508.

Hooft, E.E.E., Toomey, D.R., Solomon, S.C., 2003. Anomalously thin transition zone beneath the Galapagos Hotspot. Earth Planet. Sci. Lett. 216, 55-64.

Jordan, T.H., 1997. Lithospheric slab penetration into the lower mantle beneath the Sea of Okhotsk. J. Geophys. 43, 473-496.

Kennett, B.L.N., Engdahl, E.R., 1991. Travel times for global earthquake location and phase identification. Geophys. J. Int. 105, 429-465.

Lawrence, J.F., Shearer, P.M., 2006. A global study of transition zone thickness using receiver functions. J. Geophys. Res. 111. doi:10.1029/2005JB003973.

Lawrence, J.F., Shearer, P.M., in press. Imaging mantle transition zone thickness with SdS-SS finite-frequency sensitivity kernels. Geophys. J. Int.

Lee, C.A., Lenardic, A., Cooper, C.M., Niu, F., Levander, A., 2005. The role of chemical boundary layers in regulating the thickness of continental and oceanic thermal boundary layers. Earth Planet. Sci. Lett. 230, 379-395.

Li, A., Detrick, R.S., 2003. Azimuthal anisotropy and phase velocity beneath Iceland; implication for plume-ridge interaction. Earth Planet. Sci. Lett. 214, 153-165.

Li, X., Kind, R., Priestley, K., Sobolev, S.V., Tilmann, F., Yuan, X., Weber, M., 2000. Mapping the Hawaiian plume conduit with converted seismic waves. Nature 405, 938-941.

Li, X., Kind, R., Yuan, X., Sobolev, S.V., Hanka, W., Ramesh, D.S., Gu, Y., Dziewonski, A.M., 2003. Seismic observation of narrow plumes in the oceanic upper mantle. Geophys. Res. Lett. 30. doi:10.1029/2002GL015411.

Lowman, J.P., King, S.D., Gable, C.W., 2004. Steady plumes in viscously stratified, vigorously convecting, three-dimensional numerical mantle convection models with mobile plates. Geochem. Geophys. Geosystems 5 (1). doi:10.1029/2003GC000583.

Montelli, R., Nolet, G., Dahlen, F.A., Masters, G., Engdahl, E.R., Hung, S., 2004. Finite-frequency tomography reveals a variety of plumes in the mantle. Science 303, 338-343.

Montelli, R., Nolet, G., Dahlen, F.A., Masters, G., 2006. A catalogue of deep mantle plumes: new results from finite-frequency tomography. Geochem. Geophys. Geosystems 7 (11). doi:10.1029/2006GC001248 Q11007.

Morgan, W.J., 1971. Convection plumes in the lower mantle. Nature 230, 42-43.

Mueller, R.D., Royer, J., Lawver, L.A., 1993. Revised plate motions relative to the hotspots from combined Atlantic and Indian Ocean hotspot tracks. Geology 21, 275-278.
Natland, J.H., 1980. The Jackson Volume, vol. 280-A. Kline Geology Laboratory, Yale University, New Haven, CT, pp. 709-735.

Niu, F., Levander, A., Cooper, C.M., Lee, C.A., Lenardic, A., James, D.E., 2004. Seismic constraints on the depth and composition of the mantle keel beneath the Kaapvaal Craton. Earth Planet. Sci. Lett. 224, 337-346.

O’Nions, R.K., Tolstikhin, I.N., 1996. Limits on the mass flux between lower and upper mantle and stability of layering. Earth Planet. Sci. Lett. 139, 213-222.

Porcelli, D., Wasserburg, G.J., 1995. Mass transfer of xenon through a steady-state upper mantle. Geochim. Cosmochim. Acta 59, 1991-2007.

Putirka, K.D., 2005. Mantle potential temperatures at Hawaii, Iceland, and the mid-ocean ridge system, as inferred from olivine phenocrysts; evidence for thermally driven mantle plumes. Geochem. Geophys. Geosystems 6. doi:10.1029/2005GC000915.

Rhodes, J.M., Vollinger, M.J., 2005. Ferric/ferrous ratios in 1984 Mauna Loa lavas; a contribution to understanding the oxidation state of Hawaiian magmas. Contrib. Mineral. Petrol. 149, 666-674.

Schubert, G., Masters, G., Olson, P., Tackley, P., 2004. Superplumes or plume clusters? Phys. Earth Planet. Inter. 146, 147-162.

Shearer, P.M., 1993. Global mapping of upper mantle reflectors from long-period SS precursors. Geophys. J. Int. 115, 878-904.

Shen, Y., Solomon, S.C., Bjarnason, I.T., Wolfe, C.J., 1998. Seismic evidence for a lower-mantle origin of the Iceland Plume. Nature $395,62-65$.

Sleep, N.H., 1990. Hotspots and mantle plumes; some phenomenology. J. Geophys. Res. 95, 6715-6736.

Smyth, J.R., Frost, D., 2002. The effect of water on the 410-km discontinuity; an experimental study. Geophys. Res. Lett. 29. doi:10.1029/2001GL014418.

Sobolev, A.V., Hofmann, A.W., Sobolev, S.V., Nikogosian, I.K., 2005. An olivine free mantle source of Hawaiian shield basalts. Nature 434, 590-597.

Stixrude, L., Lithgow-Bertelloni, C., 2005. Thermodynamics of mantle minerals; I, Physical properties. Geophys. J. Int. 162, $610-632$.

Toplis, M.J., 2005. The thermodynamics of iron and magnesium partitioning between olivine and liquid; criteria for assessing and predicting equilibrium in natural and experimental systems. Contrib. Mineral. Petrol. 149, 22-39.

Van der Hilst, R.D., Widiyantoro, S., Engdahl, E.R., 1997. Evidence for deep mantle circulation from global tomography. Nature 386, 578-584.

Vinnik, L.P., 1977. Detection of waves converted from P to SV in the mantle. Phys. Earth Planet. Inter. 15, 39-45.

Walck, M.C., 1984. The P-wave upper mantle structure beneath an active spreading centre; the Gulf of California. Geophys. J. R. Astron. Soc. 76, 697-723.

Wessel, P., Smith, W.H.F., 1998. New, improved version of the Generic Mapping Tools released. EOS Trans. Am. Geophys. Union 79, 579.

Wicks Jr., C.W., Richards, M.A., 1993. A detailed map of the 660kilometer discontinuity beneath the Izu-Bonin subduction zone. Science 261, 1424-1427.

Wolfe, C.J., Bjarnason, I.T., VanDecar, J.C., Solomon, S.C., 1997. Seismic structure of the Iceland mantle plume. Nature 385, 245-247.

Workman, R.K., Hart, S.R., 2005. Major and trace element composition of the depleted MORB mantle (DMM). Earth Planet. Sci. Lett. 231, 53-72. 